\title{
Effects on pulmonary function of whole lung irradiation for Wilm's tumour in children
}

\author{
MR BENOIST, J LEMERLE, R JEAN, P RUFIN, P SCHEINMANN, J PAUPE \\ From the Laboratoire d'Exploration Fonctionnelle Respiratoire, Hôpital des Enfants Malades, Service du Pr \\ $J$ Paupe, and Institut Gustave Roussy, Service de Pédiatrie, Villejuif, France
}

ABSTRACT The effect of whole lung irradiation on lung function was investigated in 48 children treated for Wilm's tumour with pulmonary metastases. Lung function tests were performed before irradiation and were repeated annually for as long as possible, the length of follow-up varying from two to 17 years. A reduction in both lung volume and in dynamic compliance was clearly observed. In some patients these changes occurred in the early post-irradiation months, but in most the decrease observed progressed over longer periods of time. Static pressure volume curves, bloodgases, and carbon monoxide transfer were normal. These findings make it unlikely that postirradiation pulmonary fibrosis was involved. Another explanation for the decreased lung volume and dynamic compliance might be failure of alveolar multiplication. Muscular injury is unlikely as the patients were able to produce normal transthoracic pressures. A failure of chest wall growth is also possible and would explain the progressive restrictive impairment but not the early lung function changes. It is suggested that the early effects detected in some patients were the result of lung injury and that later effects resulted from impaired chest wall growth.

Although the effects of pulmonary irradiation on lung function have been extensively investigated in adults, reports on the effects on respiratory function of whole lung irradiation are relatively few and there have been no reports of detailed, repeated lung function tests after this type of irradiation.

In contrast to adults, young children are in a period of rapid lung and skeletal growth and the effect of pulmonary irradiation might be a failure of alveolar development resulting from impaired cellular proliferation, thus decreasing the number of alveoli. The aim of this study was to detect the shortand long-term pulmonary function changes in young children who received whole lung irradiation at doses which were therapeutically efficient but close to tolerance and we have tried to characterise the physiopathological mechanisms of the changes observed. Actinomycin D which enhances the effects of irradiation, was administered consecutively. ${ }^{1}$

Address for reprint requests: Dr MR Benoist, Laboratoire d'Exploration Fonctionnelle Respiratoire, Service du $\operatorname{Pr} \mathbf{J}$ Paupe, Hôpital des Enfants Malades, 149 rue de Sèvres, 75730 Paris Cedex 15, France.

\section{Methods}

Forty-eight children undergoing treatment for Wilm's tumour associated with pulmonary metastases at the Institut Gustave Roussy between 1960 and 1976 were studied. Clinical and therapeutic characteristics are summarised in table 1 . In 39 of these patients, nephrectomy was followed by irradiation of the tumour bed, including the entire width of the spine, the field extending to the hemidiaphragm. All the children received bilateral pulmonary irradiation using ${ }^{60} \mathrm{Co}$ at a dose of 20 Grays/three weeks. Actinomycin D was always given in conjunction.

Twenty-two patients were studied prospectively with initial lung function testing carried out just before pulmonary irradiation and this was denoted test " $O$ ". This information was lacking for the other 26 children who were included in the study which began in 1973. All 48 patients were subsequently tested in the same way. Measurements of lung function were repeated in each patient every six months during the first two years after pulmonary irradiation and then annually for as long as possible. 
Table 1 Clinical information

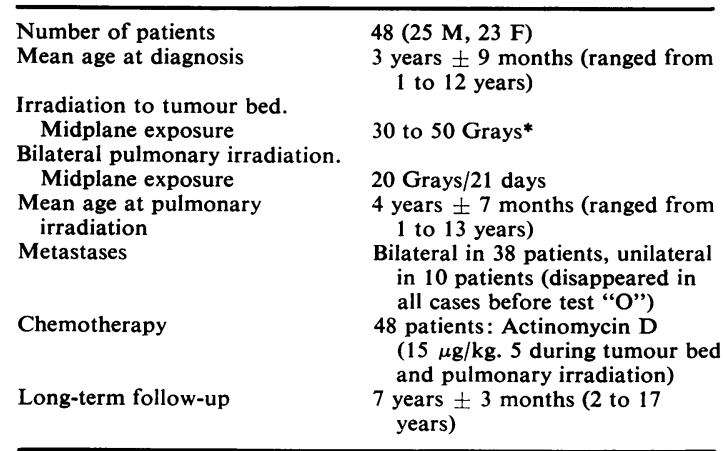

*1 Gray $=10^{-2}$ rads.

At present the length of the follow-up varies from two to 17 years.

When the cooperation of the child permitted, total lung capacity (TLC) and vital capacity (VC) were measured using a nine-litre Godart respirometer. Functional residual capacity (FRC) was determined by duplicate measurements using the helium dilution method. Volumes (BTPS) were expressed as a percentage of predicted normal values. ${ }^{2}$

Dynamic lung compliance (CLdyn) and pulmonary resistance $(\mathbf{R L})$ were determined by means of the oesophageal balloon technique. ${ }^{3}$ Length, circumference, and position were all specified in a previous study, 4 the difference between mouth and oesophageal pressure being measured with a Fenyves-Gut differential pressure transducer, and flow was measured with a Fleish pneumotachograph (number 1,2 , or 3 ) coupled to a Fenyves-Gut pressure transducer. Gas volumes were determined by electrical integration of the flow signal. Flow, volume, and oesophageal pressure changes were recorded on a three channel recorder (Rapidgraph, Sefram RPS) with a linear response curve up to 10 $\mathrm{Hz}$. Cldyn was calculated from the ratio of tidal volume to the change in transpulmonary pressure between the points of zero air flow between each inspiration and expiration. Each Cldyn value was averaged from at least 10 successive breaths at resting tidal volume. $R_{L}$ was determined by the method of Mead et $a l,{ }^{5}$ and these values were also expressed as a percentage of the predicted normal values according to height.

Lung elasticity was assessed in 18 subjects using measurements of static lung compliance (CLst) and elastic recoil pressure of the lungs (Pst). Static deflation pressure-volume (PV) curves were obtained by interrupting the expiratory airflow from TLC to residual volume (RV) for five to six four-second periods. Constant volume conditions were achieved by preceding each recorded curve with three full inflations. Transpulmonary pressure was plotted against lung volume expressed as percentage of measured TLC and the slope of the PV curve in the tidal volume range gave the static expiratory lung compliance (Clest). The values of Pst at various percentages of TLC (eg Pst insp relaxed 100, 90, 80, and so on) was obtained from the PV curves. ${ }^{6}{ }^{7} \mathrm{~A}$ line of best fit was hand drawn through at least three sets of PV data which differed by only $\pm 1 \mathrm{~cm} \mathrm{H}_{2} \mathrm{O}$. Data were compared to those obtained in 23 control subjects of the same age. ${ }^{2}$

Blood oxygen tension $\left(\mathrm{PaO}_{2}\right)$ was measured using arterialised capillary blood collected from the finger tip and was compared with predicted values similarly obtained. ${ }^{2}$ It was possible to measure $\mathrm{PaO}_{2}$ before and after exercise in 14 co-operative subjects using a bicycle ergometer (Monark). The exercise was performed for six minutes at successive loads of one-

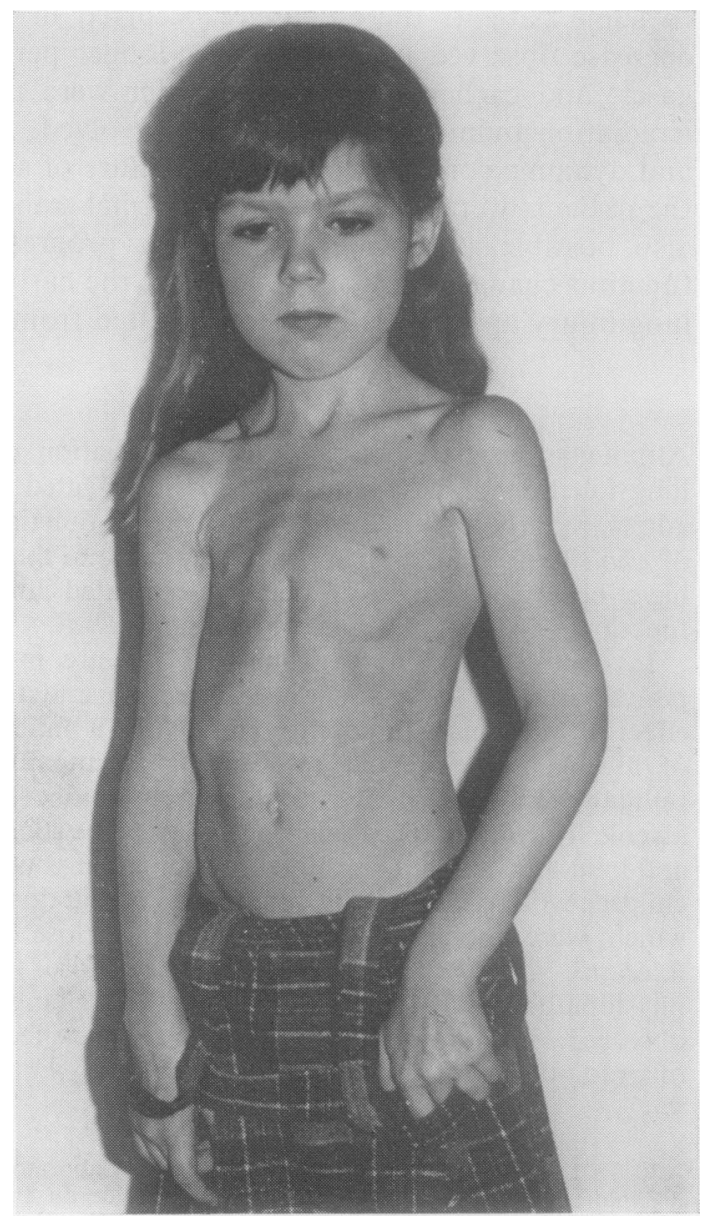

Fig 1 Thoracic hypoplasia seen in a 9-year-old girl. 
Table 2 Lung volumes, pulmonary mechanics (mean of expected values and $S D$ ) and $\mathrm{PaO}_{2}$ (arterialised capillary blood) in 11 patients followed from admission to the fourth year after irradation

\begin{tabular}{|c|c|c|c|c|c|c|c|c|c|c|c|c|}
\hline \multirow[t]{2}{*}{ Test } & \multicolumn{2}{|c|}{$F R C$} & \multicolumn{2}{|l|}{$V C$} & \multicolumn{2}{|c|}{$T L C$} & \multicolumn{2}{|c|}{ CLdyn } & \multicolumn{2}{|l|}{$R \mathbf{L}$} & \multicolumn{2}{|c|}{$\mathrm{PaO}_{2} \mathrm{mmHg}_{\mathrm{g}}$} \\
\hline & $\boldsymbol{M}$ & $S D$ & $M$ & $S D$ & $M$ & $S D$ & $M$ & $S D$ & $M$ & $S D$ & $M$ & $S D$ \\
\hline $\begin{array}{l}\text { "O" } \\
6 \text { months } \\
12 \text { months } \\
18 \text { months } \\
2 \text { years } \\
3 \text { years } \\
4 \text { years }\end{array}$ & $\begin{array}{l}97 \\
95 \\
91 \\
89^{*} \\
90^{*} \\
78 \dagger \\
71 \dagger\end{array}$ & $\begin{array}{r}14 \\
15 \\
16 \\
10 \\
17 \\
12 \\
9\end{array}$ & $\begin{array}{l}- \\
\overline{-} \\
\overline{78} \\
78 \\
72 \\
70^{*}\end{array}$ & $\begin{array}{r}12 \\
8 \\
6 \\
9\end{array}$ & $\begin{array}{l}- \\
\overline{-} \\
\overline{80} \\
79 \\
74 \\
72^{*}\end{array}$ & $\begin{array}{r}13 \\
6 \\
9 \\
7\end{array}$ & $\begin{array}{l}90 \\
68 \dagger \\
70 \dagger \\
74 \\
73^{*} \\
60 \dagger \\
60 \dagger\end{array}$ & $\begin{array}{r}19 \\
14 \\
17 \\
14 \\
13 \\
8 \\
9\end{array}$ & $\begin{array}{r}103 \\
98 \\
99 \\
97 \\
91 \\
90 \\
85\end{array}$ & $\begin{array}{r}20 \\
18 \\
11 \\
13 \\
9 \\
9 \\
12 \\
8\end{array}$ & $\begin{array}{l}88 \\
85 \\
84 \\
86 \\
92 \\
90 \\
88\end{array}$ & $\begin{array}{l}5 \\
4 \\
4 \\
4 \\
6 \\
5 \\
7\end{array}$ \\
\hline
\end{tabular}

*p $<0.05 ; \mathrm{tp}<0.02$ (paired $t$ test " $O$ " versus successive tests).

third and two-thirds of the maximum predicted for the height of the child. ${ }^{8}$

Transfer factor for carbon monoxide (TLCo) was measured in 13 subjects by the single breath method. ${ }^{9}$

\section{Results}

\section{CLINICAL}

Symptoms of radiation pneumonitis developed acutely two to three weeks after completion of radiation therapy in two of the 48 children and was characterised by non-productive cough, dyspnoea, fever and in one case progression to severe respiratory distress. The symptoms and radiographic features subsided after two months for the latter patient, and after three weeks for the remainder. On clinical examination greatly reduced sagittal and frontal thoracic diameters were observed in nearly all of the cases seen three or four years after radiation therapy (fig 1). Shortening and deformity of the lower thoracic and lumbar vertebrae within the abdominal treatment field were also observed after this follow-up for three or four years. Spinal curvatures ranging from 10 to 30 degrees were observed in 10 of the 48 subjects but these changes did not influence height, as only two subjects were below two standard deviations and one was even above the mean height for his age. The patients were not disabled and most of them experienced no dyspnoea on moderate exertion.

The chest radiographs showed no pleural or pulmonary abnormalities after the first two years after pulmonary irradiation.

\section{MEASURED LUNG FUNCTION}

As it was only possible to study some of the 48 patients over a long period, the data obtained are presented in two different ways.

First, table 2 summarises the results in 11 subjects who were followed for four years. Lung volumes and Cldyn, expressed as the mean of the percentage of the predicted values, decreased with time. Functional residual capacity decreased from $97 \%$ to $71 \%$ (p < 0.02$)$, VC from $78 \%$ to $70 \%(p<0.05)$ and Cudyn from $90 \%$ to $60 \%(\mathrm{p}<0.02)$. The reduction was more significant at the three and four year tests $(p<0.02)$ than at the one year test $(p<0.05)$.

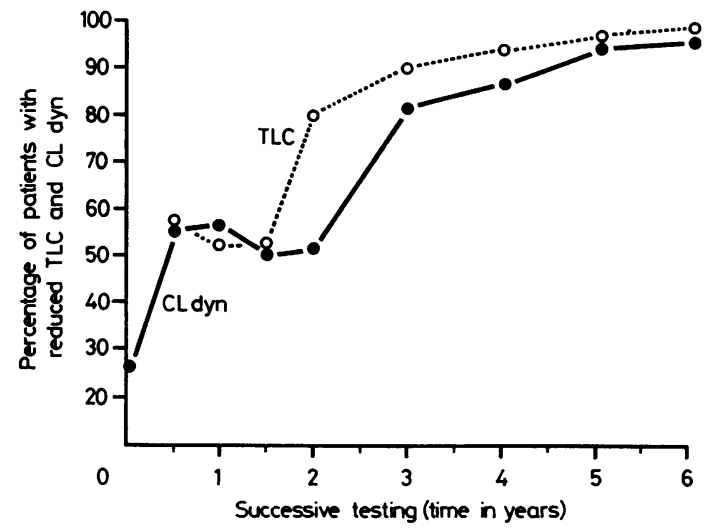

Fig 2 Percentage of patients with significantly reduced TLC and CLdyn plotted against successive tests in all 48 subjects.

Table 3 Lung volumes, pulmonary mechanics (mean of expected values and SD) and $\mathrm{PaO}_{2}\left(\mathrm{mmHg}_{\mathrm{g}}\right.$, arterialised capillary blood) obtained over test " $O$ " to $\geqslant$ six years period in all 48 subjects (part 2 ).

\begin{tabular}{|c|c|c|c|c|c|c|c|c|c|c|c|c|c|}
\hline \multirow[t]{2}{*}{ Tests } & \multirow{2}{*}{$\begin{array}{l}\text { Number } \\
\text { of } \\
\text { subjects }\end{array}$} & \multicolumn{2}{|l|}{$F R C$} & \multicolumn{2}{|l|}{$V C$} & \multicolumn{2}{|c|}{$T L C$} & \multicolumn{2}{|c|}{ CLdyn } & \multicolumn{2}{|l|}{$R \mathrm{~L}$} & \multicolumn{2}{|c|}{$\mathrm{PaO}_{2}$} \\
\hline & & $M$ & $S D$ & $M$ & $S D$ & $M$ & $S D$ & $M$ & $S D$ & $M$ & $S D$ & $M$ & $S D$ \\
\hline $\begin{array}{l}\text { "O" } \\
6 \text { months } \\
18 \text { months } \\
4 \text { years } \\
\geqslant 6 \text { years }\end{array}$ & $\begin{array}{l}22 \\
18 \\
17 \\
18 \\
15\end{array}$ & $\begin{array}{c}105 \\
91 \\
92 \\
78 \dagger \\
75+\end{array}$ & $\begin{array}{r}4 \\
11 \\
12 \\
14 \\
11\end{array}$ & $\begin{array}{l}- \\
\overline{76} \\
70 \dagger \\
61 \dagger\end{array}$ & $\begin{array}{l}11 \\
16 \\
13\end{array}$ & $\begin{array}{l}- \\
\overline{76} \\
70 \dagger \\
66 \dagger\end{array}$ & $\begin{array}{r}9 \\
13 \\
13\end{array}$ & $\begin{array}{l}86 \\
72 \\
72^{*} \\
62 \dagger \\
50 \dagger\end{array}$ & $\begin{array}{l}31 \\
29 \\
11 \\
10 \\
13\end{array}$ & $\begin{array}{r}102 \\
105 \\
99 \\
92 \\
85\end{array}$ & $\begin{array}{r}19 \\
16 \\
15 \\
9 \\
7\end{array}$ & $\begin{array}{l}89 \\
87 \\
89 \\
90 \\
91\end{array}$ & $\begin{array}{l}6 \\
7 \\
6 \\
5 \\
8\end{array}$ \\
\hline
\end{tabular}

Full data may be obtained from the authors.

* $p<0.05 ; t p<0.02$. Analysis of variance " $O$ " versus successive tests. 


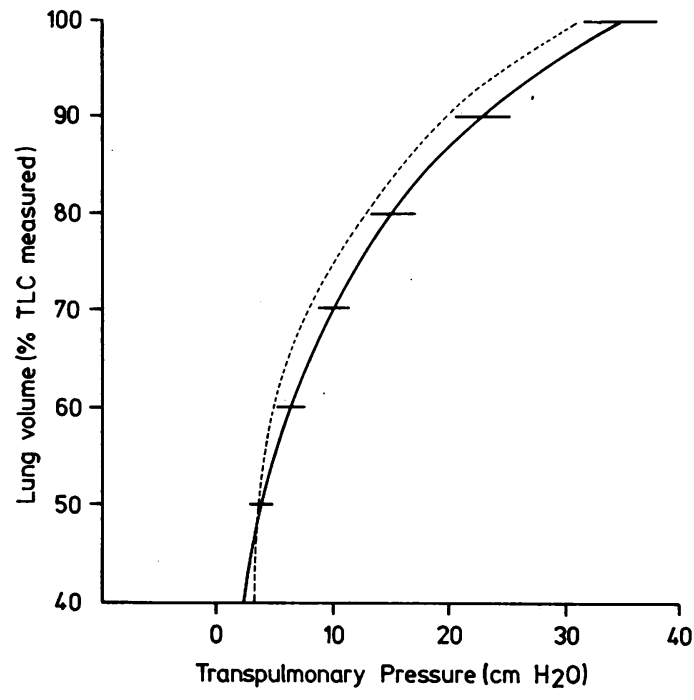

Fig 3 Mean pressure-volume curves in 18 patients, lung volume expressed as a percentage of actual TLC (-_— $) \pm I$ SEM and in 23 controls (- . - . - ).

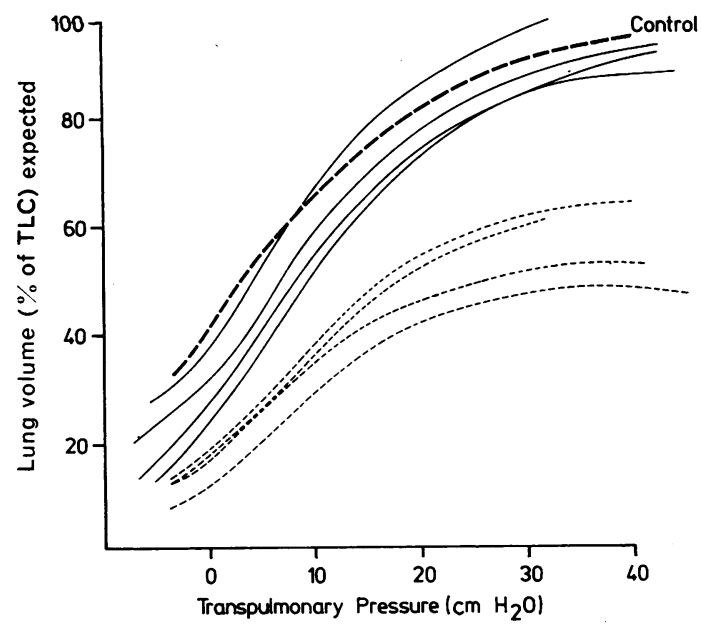

Fig 4 Pressure-volume curves in four patients. Volume expressed as percentage of actual TLC (____ $)$, as percentage of predicted TLC (- . . - - ).

Secondly, the complete data obtained from all 48 subjects by repeated testing are shown in table 3 . The period of follow-up varied between patients either because of mortality or because of recruitment for the study at a later date. In this group too, we observed a similar significant reduction in the mean values with the passage of time after pulmonary irradiation. Functional residual capacity decreased from $105 \%$ to $75 \%(p<0.02)$, TLC from $76 \%$ to $66 \%$ (p < 0.02$)$, VC from $76 \%$ to $61 \%(\mathrm{p}<0.02)$,
Table 4 Results of mechanical factors in 18 subjects tested at five years \pm three months after lung irradiation compared with 23 controls

\begin{tabular}{|c|c|c|c|c|c|c|c|}
\hline & \multirow{2}{*}{$\frac{C L d y n}{C \text { LEst }}$} & \multicolumn{5}{|c|}{ Pst $\left(\mathrm{cm} \mathrm{H} \mathrm{H}_{2} \mathrm{O}\right)$} & \multirow{2}{*}{$\frac{C_{\text {LEST }}}{V C}$} \\
\hline & & $\begin{array}{l}100 \\
\% \text { of }\end{array}$ & $\begin{array}{c}90 \\
T L C\end{array}$ & $\begin{array}{c}80 \\
\text { meas }\end{array}$ & $\begin{array}{c}70 \\
\text { red }\end{array}$ & 60 & \\
\hline \multicolumn{8}{|l|}{ Patients } \\
\hline Mean & 81 & 34 & 26 & 17 & 12 & 8 & 0.033 \\
\hline \multicolumn{7}{|l|}{ Controls } & 0.005 \\
\hline Mean & 85 & 37 & 25 & 16 & 10 & 8 & 0.038 \\
\hline SD & 13 & 6 & 5 & 3 & $2 \cdot 5$ & 3 & 0.007 \\
\hline
\end{tabular}

$1 \mathrm{~cm} \mathrm{H} \mathrm{H}_{2} \mathrm{O}=0.1 \mathrm{kPa}$.

and Cldyn from $86 \%$ to $50 \%(\mathrm{p}<0.02)$. The number of patients with reduced values increased with time after irradiation (fig 2).

In the tests taken as a whole, there were more reduced values of VC and TLC than FRC $(\mathrm{p}<0.001)$ and the decrease in Cudyn was more pronounced than that of lung volume $(p<0.001)$. The $R_{L}$ values were not significantly different from the predicted values for every patient at each testing (tables 2, 3). Pressure-volume curves obtained for 18 patients after five $\pm \mathbf{2 . 9}$ years follow-up were no different from those of 23 controls when Pst was

Table 5 Results of lung transfer for $\mathrm{CO}$ and $\mathrm{PaO}_{2}$ before and after exercise

\begin{tabular}{|c|c|c|c|c|}
\hline & \multirow{2}{*}{$\begin{array}{l}T \mathrm{LCO}(\mathrm{SB}) \% \\
\text { of expected } \\
\text { for height }\end{array}$} & \multirow{2}{*}{$\begin{array}{l}T \mathrm{LCO}(\mathrm{SB}) \% \\
\text { of expected } \\
\text { corrected for } \\
\text { lung volume }\end{array}$} & \multicolumn{2}{|c|}{$\mathrm{PaO}_{2}$ torrs } \\
\hline & & & $\begin{array}{l}\text { Before } \\
\text { exercise }\end{array}$ & $\begin{array}{l}\text { After } \\
\text { exercise }\end{array}$ \\
\hline Mean & 72 & 112 & 85 & 87 \\
\hline SD & 8 & 11 & 6 & 7 \\
\hline & 13 & 13 & 14 & 14 \\
\hline Years elapsed & $6 \pm 4$ & $6 \pm 4$ & $6 \pm 4$ & $6 \pm 4$ \\
\hline
\end{tabular}

TLCO (SB) = transfer capacity for $\mathrm{CO}$, single breath method; $\mathrm{n}=$ number of subjects; $\mathrm{kPa}=7.5$ torrs.

related to measured lung volume (fig 3) but when compared with expected lung volume, the curves were found to be displaced downwards and to the right (fig 4).

Transpulmonary pressure measured at various percentages of TLC was not increased (table 4) and Clest was higher than Cldyn, as is usual in healthy children. ${ }^{1011}$ The mean ratio of CLest with VC was not significantly lower than in healthy children (table 4).

Arterial oxygen tension was within the normal limits on every test (tables 2, 3). Post-exercise $\mathrm{PaO}_{2}$ was not reduced in 14 children tested after six years (table 5).

Mean Tlco was found to be significantly reduced in 13 patients tested after six years follow-up: $72 \pm 8 \%$ of the predicted value for height ( $\mathrm{p}<0.02$ ), but was no lower than predicted for lung volume: $112 \pm 11 \%$ (table 5 ). 


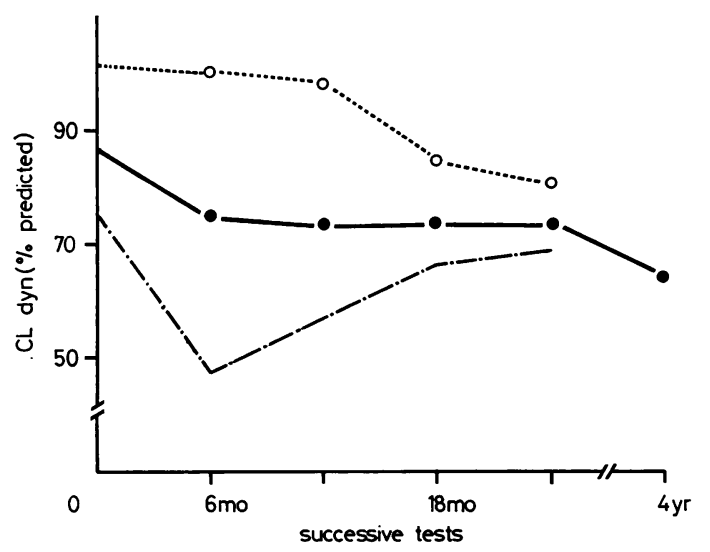

Fig 5 Time-course of changes in CLdyn in all patients (O), in nine subjects with early fall in CLdyn (-......) and in nine subjects with initially preserved values $(\bigcirc)$.

\section{Discussion}

A restrictive ventilatory impairment and thoracic hypoplasia were clearly observed in the children in our study. This decrease in lung volume was similar to that found by Wohl' ${ }^{12}$ in six patients tested seven to 13 years after undergoing similar treatment but with lower radiation exposure.

Three chronological phases could be defined in the present study. The first, observed during the early post-irradiation months, was characterised by deteriorating lung function. The second spanned the next two years when no further deterioration was seen. The third phase occurred after the second year and was characterised by both progressively decreasing mean values and an increased number of patients with abnormal lung volume and CLdyn (fig 2).

These chronological changes may be the result of different pathological processes, the first of which is early lung disease. Thus at the six-month test (fig 5) nine of the 18 patients tested showed a drop in CLdyn (mean $48 \%$ of predicted, range $30 \%$ to $58 \%$ ). Two of them relapsed with severe pulmonary metastases and died some months later with respiratory distress symptoms, while two others showed increased bronchovascular markings and basal blurring on the chest radiograph and two patients had evidence of interstitial pneumonitis. However no explanation for the deterioration in lung function could be found in the other three subjects. In the remaining nine patients tested at six months, no deterioration in Cldyn was observed (mean Cldyn $95 \%$ of predicted, range 111 to $72 \%$ ).

One year later, at the 18-month test (fig 5), the mean Cldyn of the seven surviving subjects had improved (mean Cldyn $67 \%$ of predicted). It is likely that the apparent stability of the mean values observed during the second phase was caused by a combination of improved lung function in some subjects, and omission of low values as a result of deaths in two others. During the third phase, progressive deterioration could be explained by some lung parenchymal sequelae of acute lung injury and by the deleterious effects of radiation on lung and/or chest-wall growth.

Several physiopathological mechanisms might explain these persistent changes. Pulmonary fibrosis was considered as a possibility; however as previously seen only two subjects showed evidence of interstitial pneumonitis and we found no increase in Pst (L) measured after five years in 18 subjects, of whom five exhibited early lung function deterioration such as is found in adults with pulmonary fibrosis. Elastic pressures have been measured by Yernault, ${ }^{13}$ Macklem, ${ }^{14}$ West, ${ }^{15}$ and Gibson ${ }^{16}$ at different measured lung volumes and the static PV curves were clearly shifted downwards and to the right when compared with normal curves. In contrast, the PV curves in our 18 subjects remained similar to those of healthy subjects. Two other findings make fibrosis unlikely: first, post-exercise $\mathrm{PaO}_{2}$ was no lower than that before exercise in 14 patients, three of whom exhibited greatly decreased CLdyn at the six-month test; secondly, TLCo was normal in all measurements when related to the measured TLC.

Another possible explanation for decreased volume and Cldyn might lie in injury to alveoli and peripheral airways which could have been destroyed or failed to develop at this age when there is normally intensive alveolar multiplication. The more marked reduction in Cldyn compared with lung volume may be caused by ventilatory asynchrony resulting from injury, with unequal changes in the calibre of the peripheral airways. To the extent that reduction in size or number of alveoli may be comparable to a

Table 6 Lung volume and CLdyn in 17 children with renal treatment but without pulmonary irradiation

\begin{tabular}{|c|c|c|c|c|c|c|c|c|c|}
\hline \multicolumn{2}{|c|}{ Tests in years } & \multicolumn{2}{|l|}{ CLdyn } & \multicolumn{2}{|l|}{$F R C$} & \multicolumn{2}{|l|}{$V C$} & \multicolumn{2}{|l|}{$T L C$} \\
\hline Mean & $S D$ & $\begin{array}{l}\text { Mean \% } \\
\text { of } \\
\text { expected }\end{array}$ & $S D$ & $\begin{array}{l}\text { Mean \% } \\
\text { of } \\
\text { expected }\end{array}$ & $S D$ & $\begin{array}{l}\text { Mean \% } \\
\text { of } \\
\text { expected }\end{array}$ & $S D$ & $\begin{array}{l}\text { Mean \% } \\
\text { of } \\
\text { expected }\end{array}$ & $S D$ \\
\hline 5 & 4 & 92 & 8 & 96 & 12 & 83 & 7 & 88 & 91 \\
\hline
\end{tabular}


pneumonectomy, Cldyn might be reduced according to reduction in lung volume. It may be seen from the PV curves that, at normal predicted pressure, lung volume was smaller than expected. This finding suggests a reduction in the number of alveoli. An alteration in lung growth may induce a parallel alteration in chest-wall growth, leading to a small lung in a small thorax.

Alternatively, it is possible that impairment in some subjects was caused primarily by muscular or skeletal injury. Muscular damage to the diaphragm from radiotherapy might occur after the irradiation of the tumour bed but in 17 subjects with similar renal treatment without pulmonary irradiation, no significantly reduced values were observed (table 6). Intercostal muscle weakness is also a possible consequence of thoracic irradiation. We did not record the maximum static respiratory pressures, recently described by De Troyer ${ }^{17}$ and requiring good motivation and cooperation from the subjects, but it is unlikely that respiratory muscle strength was decreased in subjects who were able to perform normal Pst. Skeletal radiation damage identical to the vertebral body changes seen after the kidney tumour bed irradiation is also possible. ${ }^{1819}$ If thoracic hypoplasia, which increases with the passage of time, is caused by failure of chest-wall growth, this could explain the progressive diminution of lung volume but not the early functional changes.

It is therefore likely that pulmonary irradiation had direct consequences, either on the pulmonary parenchyma or on skeletal growth and that in some of the patients tested, these various mechanisms may be involved in functional pulmonary abnormalities. In some patients the early primary phenomenon was that of lung injury, with deleterious later effects on both lung and skeletal structures, while in other patients a reduction in chest-wall growth might be solely responsible for these changes.

Our results in these patients suggest relatively wellpreserved function despite a whole lung radiation dose which was close to the limit of tolerance. Nevertheless, it must be emphasised that spinal curvature may deteriorate at puberty, causing further impairment in lung function, so that continued follow-up up to and beyond puberty is essential.

\section{References}

${ }^{1}$ Margolis LW, Phillips TL. Whole lung irradiation for metastatic tumor. Radiology 1969;93:1173-9.

${ }^{2}$ Jean R, Benoist MR. Exploration fonctionnelle en pédiatrie. First edition. Paris: Flammarion, 1979.

${ }^{3}$ Milic-Emili G, Mead J, Turner JM, Glauser EM. Improved technique for estimating pleural pressure from oesophageal balloons. J Appl Physiol 1964;19:207-11.

- Benoist MR, Siguier C, Fermanian J, Jean R, Paupe J, Vialatte $J$. Lung function after neonatal respiratory distress syndrome. Bull Europ Physiopathol Respir 1976; 12:703-14

${ }^{5}$ Mead J, Whittenberger JL. Clinical measurement of resistive and elastic properties of the lung. $J$ Clin Invest $1953 ; 32: 588-9$.

${ }^{6}$ Colebatch HJH, Greaves IA, Ng EKY. Exponential analysis of elastic recoil and aging in healthy males and females. $J$ Appl Physiol 1979;47:683-91.

' Finucane KE, Colebatch HJH. Elastic behaviour of the lung in patients with airway obstruction. J Appl Physiol $1969 ; 26: 330-43$.

${ }^{8}$ Godfrey S. Exercise testing in children. Philadelphia: Saunders, 1974.

${ }^{9}$ Ogilvie CM, Forster RE, Blakemore WS, Morton JW. A standardised breath holding technique for the clinical measurement of the diffusing capacity of the lung for carbon monoxide. J Clin Invest 1957;36:1-17.

${ }^{10}$ Van der Hardt H, Logvinoff MM, Dickreiter S, Geubelle F. Static recoil of the lungs and static compliance in healthy children. Respiration $1975 ; 32: 325-39$.

${ }^{11}$ Zapletal A, Paul T, Samanek M. Pulmonary elasticity in children and adolescents. J Appl Physiol 1976;40:953-61.

12 Wohl ME, Griscom NT, Traggis DG, Joffe N. Effects of therapeutic irradiation delivered in early childhood upon subsequent lung function. Pediatrics 1975 ;55:507-16.

${ }^{13}$ Yernault JC, De Jonghe M, De Coster A, Englert M. Pulmonary mechanics in diffuse fibrosing alveolitis. Bull Europ Physiopathol Respir 1975;11:231-44.

${ }^{14}$ Macklem PT, Becklake MR. The relationship between the mechanical and diffusing properties of the lung in health and disease. Am Rev Respir Dis 1963;87:47-58.

15 West JR, Alexander JK. Studies on respiratory mechanics and the work of breathing in pulmonary fibrosis. $\mathrm{Am} \mathrm{J}$ Med 1959;27:529-44.

${ }^{16}$ Gibson GJ, Pride NB. Lung distensibility in pulmonary fibrosis. Bull Europ Physiopathol Respir 1973;9:1250-1.

${ }^{17}$ De Troyer A, Yernault JC. Inspiratory muscle force in normal subjects and patients with interstitial lung disease. Thorax 1980;35:92-100.

${ }^{18}$ Oliver JH, Gluck G, Gledhill RB, Chevalier L. Musculoskeletal deformities following treatment of Wilm's tumor. Can Med Assoc J 1978;119:459-64.

${ }^{19}$ Heaston DK, Libshitz HI, Chan RC. Skeletal effects of megavoltage irradiation in survivors of Wilm's tumor. AJR 1979;133:389-95. 